Review

\title{
Metastable state of gas hydrate during decomposition: A novel phenomenon
}

\author{
Ronghui Sun ${ }^{1}$, Zhen Fan ${ }^{2}$, Lei Yang ${ }^{1, *}$, Yuanping Li $^{3}$, Xin L $\ddot{u ̈}^{4}$, Yang Miao ${ }^{5}$ \\ ${ }^{1}$ Key Laboratory of Ocean Energy Utilization and Energy Conservation of Ministry of Education, Dalian University of Technology, Dalian 116023, China \\ 2 School of Chemistry, University of Glasgow, Glasgow G12 8QQ United Kingdom \\ ${ }^{3}$ Institute of Science and Technology, Shenzhen Branch, China National Offshore Oil Corporation, Guangzhou 510420, China \\ ${ }^{4}$ CNOOC Research Institute Co. Ltd, Beijing 100028, China \\ ${ }^{5}$ Xingang Shipbuilding Heavy Industry Co., Ltd., Tianjin 300452, China
}

\section{A R T I C L E I N F O}

\section{Article history:}

Received 6 December 2018

Received in revised form 26 September 2019

Accepted 7 February 2020

Available online 19 February 2020

\section{Keywords:}

Hydrates

Dissociation

Metastability

Self-preservation

Supersaturation

\begin{abstract}
A B S T R A C T
Natural gas hydrates are solid compounds with cage-like structures formed by gas and water. An intriguing phenomenon that gas hydrates can dissociate at a low rate below the ice freezing point has been viewed as the metastability of hydrate. The mechanisms of hydrate metastability have been widely studied, and many mechanisms were proposed involving the self-preservation effect, supercooled water-gas-hydrate metastable equilibrium, and supersaturated liquid-gas-hydrate system etc. The metastable state of hydrate could be of crucial significance in the kinetics of hydrate formation and decomposition, heat and mass transfer during gas production processes, and the application of hydrate-based technique involving desalination, energy storage and transportation, and gas separation and sequestration. Few researches have systematically considered this phenomenon, and its mechanism remains unclear. In this work, various mechanisms and hypothesis explaining the metastable state of gas hydrates were introduced and discussed. Further studies are still required to reveal the intrinsic nature of this metastable state of gas hydrate, and this work could give some implications on the existing theory and current status of relevant efforts.
\end{abstract}

(C) 2020 The Authors. The Chemical Industry and Engineering Society of China, and Chemical Industry Press Co., Ltd.

All rights reserved. This is an open access article under the CC BY-NC-ND license (http://creativecommons.org/ licenses/by-nc-nd/4.0/).

\section{Introduction}

Natural gas hydrates (NGHs) are non-stoichiometry compounds with hydrogen-bonded water cages acting as host and gas molecules as guest [1-3]. The guest gas molecules involve methane, ethane, propane, and carbon dioxide, etc., among which methane attracts much attention due to its potential in energy source and gas storage [4-6]. There are three different clathrate structures of gas hydrates, namely two cubic structures s I and s II, and one hexagonal structure s H. The clathrate structure was found to be dependent upon the size of the guest molecule [7]. Gas hydrates were first observed by Priestley in 1778 and documented by Davy in 1811 [8]. Since the year of 1934, the existence of natural gas hydrates was found to be the trigger of blockages in pipelines during the transportation of natural gas [9]. The discovery of large amount of hydrate reservoirs in the permafrost and under the continental shelf during the period from the mid-1960 till present made NGH one of the most important energy resources; to develop methods for commercial production of natural gas from hydrate reservoirs is thus attracting considerable attention worldwide [10,11]. Natural gas hydrates are considered to contain almost $1 / 3$ of world's mobile organic carbon and each volume of hydrate

\footnotetext{
* Corresponding author.

E-mail address: leiyang@dlut.edu.cn (L. Yang).
}

can produce 164 volumes of natural gas [12]. Many countries have proposed national strategies on gas production from NGH as well as their significant environmental aspects. The U.S. have been a leading country in the development of gas hydrate and have taken legislative approach to secure NGH as a crucial energy resource [13]. Japan is one of the countries that approved a national program on NGH firstly and a three-phaseprogram the "Research Consortium for Methane Hydrate Resources in Japan" was conducted [14]. China started programs on NGH in 2002; the first field test in China was conducted in 2017, producing natural gas for 60 successive days [15].

Hydrate has also been widely used in various industry-related techniques, involving storage and transportation of natural gas, sea water desalination, cold energy storage, gas separation etc. [16-20]. The upscale and commercial application of these techniques suffer from the sluggish formation process, insufficient transformation and limited capacity. These make the thermodynamics and kinetics of hydrate formation and dissociation of great significance [21]. Three main processes for hydrate dissociation (thermal stimulation, depressurization and inhibitor injection) have been proposed [22-24]. The thermodynamic equilibrium conditions of the hydrates govern the formation and dissociation process of hydrates $[4,25,26]$; thus, the determination and regulation of hydrate phase equilibria have always been a significant issue in hydrate related study [27]. 
In the phase diagram of hydrate, the equilibrium curve can be divided into stable zone and unstable zone. Hydrates can only remain a thermodynamic equilibrated state when the pressure and temperature locate within the stable zone; otherwise the pressure and temperature conditions in the unstable zone will trigger hydrate decomposition. However, an intriguing phenomenon has been observed during hydrate formation and dissociation; hydrate may not be generated even after a long period of time (induction period) in the stable zone [28]; hydrate may also decompose at an anomalously low rate in the unstable zone [29]. These phenomena are identified as a performance of metastability of hydrate. The metastable state was defined as "a define equilibrium which is, nevertheless, not the most stable equilibrium at the given temperature" [30]. Jan Lubas proposed the "area of hydrate metastability; he considered that the hydrate formation and dissociation curve may not coincide and the area between these curves is "the area of hydrate metastability" [31]. According to Skripov, a metastable state corresponds to a local minimum of the system free energy at given external conditions and the depth of the minimum determines the stability and lifetime of the metastable state [32].

Hydrates may persist in a metastable state for millions of years under the seafloor or in the permafrost [33]. This indicates the significant geological importance of hydrate stability as the metastable hydrates may likely decompose upon a slight fluctuation of the ambient conditions, which would possibly trigger a strata failure along the continental margins thereby contributing to the greenhouse effect [34,35]. On the other hand, the metastability can also be applied in the gas storage and transportation using hydrates and pressure regulation during gas production from hydrates [16,36-38].

The development of researches on hydrate metastability during dissociation can be classified into three stages, as shown in Table. 1.

- The first stage (studies on the role of ice in hydrate metastability):

This stage was from the time the retarded decomposition of gas hydrate was discovered in 1968 till present. During this period, the mechanism of the sluggish decomposition was attributed to the formation of an almost impermeable ice shell on the surface of the hydrate during decomposition, preventing gas from escaping to the surroundings. Researches of hydrate metastability were mainly focused on the role of ice in the relic dissociation of hydrate $[29,43,56]$. Early study found that the hydrates in finely powdered and large crystal form would undergo different dissociation procedures, yet without microstructural

Table 1

Studies about hydrate metastability during the three periods

\begin{tabular}{|c|c|}
\hline Stage & Representative efforts \\
\hline $\begin{array}{l}\text { Stage I } \\
\text { (studies on the role of ice in } \\
\text { the hydrate metastability) }\end{array}$ & $\begin{array}{l}\text { Retarded decomposition of gas hydrate was } \\
\text { observed [39] } \\
\text { Experiments were carried out to explain the } \\
\text { self-preservation [40] } \\
\text { Models were introduced to explain the } \\
\text { self-preservation [41,42] } \\
\text { The effect of different factors on self-preservation } \\
\text { was investigated }[43,44]\end{array}$ \\
\hline $\begin{array}{l}\text { Stage II } \\
\text { (studies on the intermediate } \\
\text { metastable phase of ice) }\end{array}$ & $\begin{array}{l}\text { Early description of metastable two-phase } \\
\text { ice/hydrate equilibrium [45] } \\
\text { The shielding effect of ice remains skeptical } \\
\text { [46,47] } \\
\text { Transformation process from ice Ic to ice Ih was } \\
\text { observed }[48,49]\end{array}$ \\
\hline $\begin{array}{l}\text { Stage III } \\
\text { (more mechanisms of hydrate } \\
\text { metastability) }\end{array}$ & $\begin{array}{l}\text { Specific classification of hydrate metastability } \\
\text { was presented [50] } \\
\text { Formation of supercooled liquid water during } \\
\text { hydrate dissociation was firstly detected [51-53] } \\
\text { A metastable superheated solid phase of } \\
\text { methane hydrate was presented when studying } \\
\text { effects of bubbles on the kinetics [54] } \\
\text { Enrichments of guest molecules in the water was } \\
\text { in-situ observed at a sub-micron resolution [55]. }\end{array}$ \\
\hline
\end{tabular}

understandings of the role of ice [41]. Then, models were introduced to explain the self-preservation [41,42]. The effect of different factors on self-preservation was investigated $[43,44]$.

- The second stage (studies on the intermediate metastable phase of ice):

This stage was from around 1990 till present, during which more attentions were placed on the effect of metastable water/ice phase on the presence of self-preservation phenomenon. Re-crystallization was considered to take place at the ice-hydrate interface, accompany mutual hydrate-ice transformation. This phenomenon was described as a metastable two-phase hydrate-ice equilibrium [45]. However, queries still exist on the dominant shielding effect of ice on the gas diffusion from hydrates $[46,47]$. The annealing of stacking faults of the ice was not well understood until the neutron diffraction and cryo-SEM studies were carried out $[48,49]$.

- The third stage (more mechanisms of hydrate metastability):

This stage started from 2011 when a systematic and detailed classification of hydrate metastability was introduced by Istomin [50]. The formation of supercooled liquid water during dissociation of hydrate was for the first time detected [51-53]. A metastable superheated solid phase of methane hydrate was presented when studying the effect of bubbles on the kinetics of hydrate decomposition [54]. The enrichments of guest molecules in the water were not easily observed until the synchrotron micro-tomography with a sub-micron resolution was used [55]. These enrichments provide evidences of the existence of gas in the form of nanobubbles [57].

\section{Role of Ice in The Metastability of Hydrate}

Retarded decomposition of gas hydrates in Eastern Siberia was first observed by Makogon in a transportation pipeline in 1968. Afterwards, an assumption was made that the "relic gas hydrate" could exist for a long period based on the field and laboratory data [39,51,52]. The ideas of self-preservation and were early proposed by Russian researchers [29]. The hydrate decomposition at a slow rate was attributed to the generated ice film covering the hydrate surface below the three phase equilibrium point of the gas-water-hydrate (usually under atmospheric pressure) [58]. This phenomenon was regarded as a phenomenon of hydrate metastability. The self-preservation phenomena were found to play a crucial role in the kinetics of hydrate decomposition and potential application in preserving gas hydrate at moderate conditions during gas storage and transportation. A number of studies have been carried out to investigate the mechanism of self-preservation $[29,40,41,43,56]$.

It was assumed that the ice film was generated during initial hydrate dissociation resulting in the anomalous dissociation behavior of hydrate. This indicates that the metastable system includes a superheated phase (hydrate) covered by a thermodynamic stable phase (ice). Some researchers proposed that the ice-hydrate interface may play a role in the metastable behavior of hydrate as the channels available for gas escape to the surroundings would be blocked by the dense ice phase $[46,47]$. The metastability of hydrates is also attributed to the insufficient heat supply required to dissociate the hydrate [59].

To explain the anomalous stability of hydrate at non-equilibrium conditions, the dissociation rates of $\mathrm{Xe}$ and $\mathrm{Kr}$ hydrates with different grain sizes were investigated using a Tian-Calvet heat flow calorimeter. Powder samples of Xe and $\mathrm{Kr}$ hydrates were found to dissociate in one step below $273 \mathrm{~K}$; bigger samples dissociated in two steps: initially into ice and gas then ice began to melt after the temperature reached around $273 \mathrm{~K}$ [56]. Studies on the decomposition rate of methane hydrate at low temperatures also attributed the suppression of initial rapid dissociation to the formation of ice on the surface of dissociating hydrate [60]. However, the directly observation of the ice film was not 
available until cryo-SEM technique was used [49,61,62]. In addition, it was referred to that substantial superheated ice I $\mathrm{h}$ (in view of the difficulty to evaluate the local temperature, the "superheated" state is not consolidated) can exist at least for hours when covered with a protective layer of hydrate, which is a reverse process of self-preserved hydrate $[63,64]$. It was also proposed that methane hydrate can exist at a metastable state at $283 \mathrm{~K}$ and $0-1 \mathrm{MPa}$ when covered by a hydrate with heavy guest (propane or iso-butane) which is thermodynamically stable at the same conditions $[63,65]$. According to Japanese researches using X-ray diffraction technique and scanning electron microscope, it was confirmed that the thin ice film was formed during hydrate dissociation, slowing down the dissociation rate $[66,67]$. The effects of the SDS on the metastable state of gas hydrate upon decomposition below ice point were also investigated [68]. The presence of SDS was found to increase the meta-stable system pressure in the temperature region lower than $269.4 \mathrm{~K}$; at a higher temperature, the SDS accelerated the dissociation process in the beginning, followed by an inhibiting effect several hours later and a resulting lower meta-stable system pressure. Besides, the compaction of hydrate samples after formation was found to lower its stability and increase the dissociation rate [69].

Models were introduced to explain the self-preservation phenomenon. Van der Waals-Platteeuw model was used to confirm that in particular pressure-temperature regions hydrate can be converted into ice [29]. The mechanical properties of ice were also considered in icehydrate systems; the tensile strength of ice was found more sensitive to grain size than to temperature [42]. Thus the dissociation of hydrate would be suppressed due to the mechanical strength of the ice. It was concluded that the maximum volume fraction of hydrate allowing existence of metastable state at ambient pressure was inversely proportional to the temperature and hydrate grain size [60]. In the mathematical model describing the decomposition kinetic behavior of hydrates below ice point, the diffusivity of guest molecules through the ice shell was also proposed as a crucial factor [70].

More experiments were carried out to investigate the effect of hydrate properties and conditions on the self-preservation phenomena. It was found that s I and s II hydrates showed similar behaviors in selfpreservation and little effect of hydrate structure on the dissociation rate was discovered [29]. Yet, hydrate of cubic structure II was claimed to show less self-preservation than cubic structure I, which was explained by the stochastic characteristics of hydrate metastability [44]. The effects of humidity of the surroundings, air circulation, electromagnetic radiation, and temperature were also investigated. Their roles in the stability of hydrates turned out to be affecting the ice sublimation [43]. The gas loss of the hydrate samples containing comparable amounts of ice during the storage at ambient pressure was also found to increase with temperature [59]. Besides, the time duration of hydrates remaining stable increased with the size of hydrate grain $[45,71]$. These all support the protecting effect of the ice layer coating the hydrate surface acting as a mass transfer barrier for the gas from hydrate into the ambient through the icing [64].

\section{Intermediate Metastable Phase of Ice}

An assumption was proposed that the initial stage of the selfpreservation was accompanied with the evolution of several intermediate metastable phases of ice: supercooled water, cubic crystalline ice and/or amorphous ice. The most probable mechanism was that hydrate decomposed initially into liquid supercooled water film, followed by the supercooled water gradually transforming into ice. Between the hydrate and ice existed a dynamic layer of supercooled water [45], as shown in Fig.1. Different pressure-temperature-time paths were found to play a role in the hydrate kinetics and stability. In the temperature ramping process from $195 \mathrm{~K}$ to $271 \mathrm{~K}$, an abnormal dissociation rate of hydrate was found to appear in the range of $240 \mathrm{~K}$ to $271 \mathrm{~K}$ [46,47]. This cannot be merely attributed to the ice shell since it can also be generated below $240 \mathrm{~K}$ [72]. Thus a hypothesis was proposed that a static film of quasiliquid water existed on the surface of ice above $240 \mathrm{~K}$ [73]. According to neutron diffraction and SEM analysis, evidence of thin cubic ice film generation during hydrate dissociation below $240 \mathrm{~K}$ was obtained; it can also be transformed to hexagonal ice. The cubic was found to show multiple crystalline flaws, effectively preventing gas diffusion. While hexagonal ice provided no crystalline imperfections appearing impenetrable for gas. The performance of self-preservation in various temperature windows was also examined $[48,49]$. The three-phase equilibrium curves based on thermodynamic computation are shown in Fig.2. The self-preservation of hydrate can be controlled through operating the pressure and temperature conditions.

\section{More Mechanisms of Hydrate Metastability}

In 2011, a more specific classification of the metastable states of gas hydrate was proposed based on the thermodynamic state of gas hydrate, quantity of phases in the system and various metastable aqueous phases [50], as shown in Fig.3. In particular, the metastability in hydrate decomposition involve two cases: (1) metastable state of gas hydrate phase (concentrated studies on the self-preservation effect, with few efforts on the hydrate phase with insufficient cage fillings [74]); (2) metastable equilibria (involving supercooled water-gas-gas hydrate, cubic a

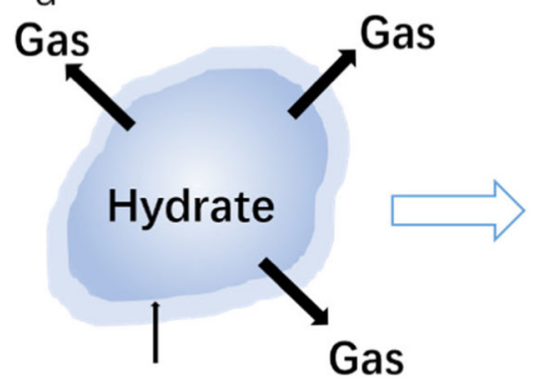

Super-cooled

water b c

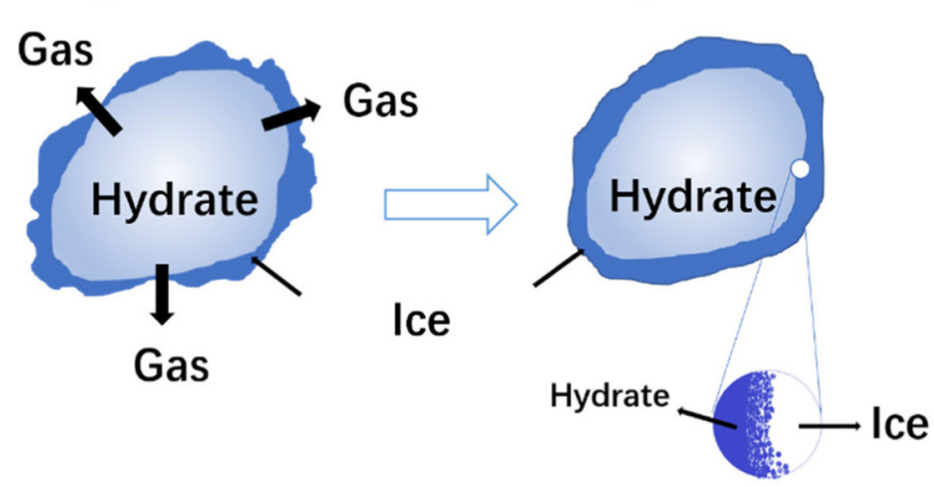

\section{Refreezing zone}

Fig. 1. Self-preservation phenomenon of gas hydrate particle upon decomposition (modified from [58]). 


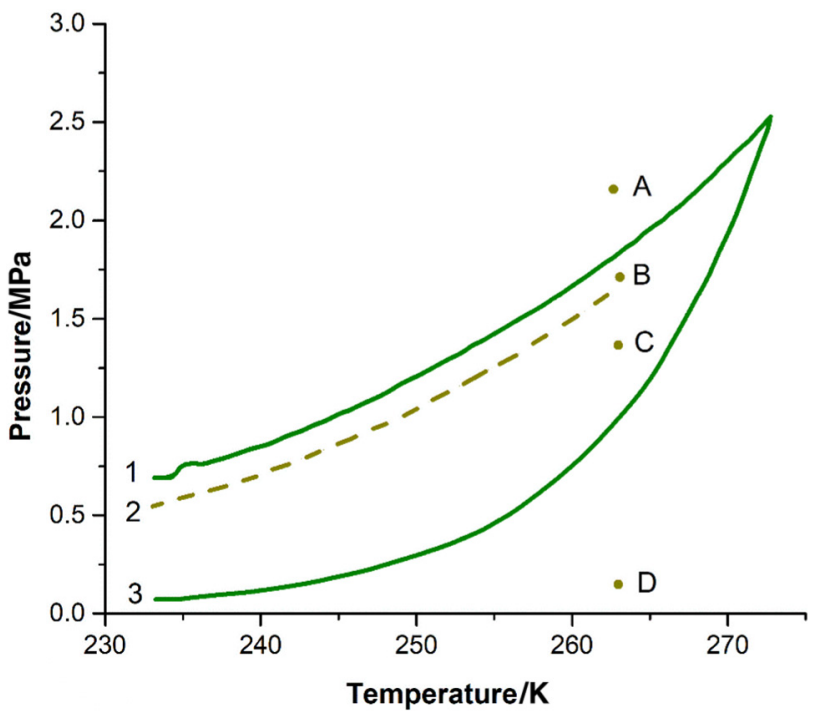

Fig. 2. Computed data of three-phase equilibrium of methane - water - hydrate system at temperatures below $272.95 \mathrm{~K}$. Curve 1: Methane-hexagonal ice-hydrate system; curve 2: methane-cubic ice-hydrate system; curve 3: Methane-supercooled water-hydrate system. Point A represents the initial state of the methane-hydrate system. Depressurization down to $0.1 \mathrm{MPa}$ (Point D) results in the generation of supercooled water on the surface of the hydrate particles upon the initial decomposition. Depressurization down to 1.0-1.8 MPa (Point C) makes the existence of supercooled water almost impossible. Depressurization to point $\mathrm{B}$ will help the formation of hexagonal ice on the hydrate surface. (modified from [58]).

ice-gas-gas hydrate, amorphous water-gas-gas hydrate and liquid water-superheated liquefied gas-gas hydrate) [50].

Besides the self-preservation, attentions are also paid to other possible metastable states of hydrate during decomposition. At the temperature below $273 \mathrm{~K}$, it was also proposed that hydrates may first decompose into liquid water and gas followed by the liquid water transforming into ice (rather than directly decomposing into ice and gas). The super-cooled water was considered to play an important role in this process [52]. Experimental evidences for the generation of liquid water during bulk hydrate dissociation below $273 \mathrm{~K}$ were also obtained by the use of visualization apparatus such as optical microscopy, X-ray CT and nuclear magnetic resonance [51,53]. It was observed that hydrate will immediately decompose rapidly upon ice generation; the long lifetime of metastable hydrates suggested the presence of a significant energy barrier (the activation energy) for ice nucleation on the hydrate surface [75]. By comparing the hydrate-ice-gas, hydratewater-ice equilibrium curve and the metastable equilibrium curve, it is discovered that the metastable equilibrium curve is an extension of the hydrate-liquid water-gas equilibrium curve into the temperature region below $273 \mathrm{~K}$; the region between the hydrate-ice-gas and the hydrate-liquid water-gas equilibrium in the P-T phase diagram is considered the metastable region of gas hydrate [76]. Two distinctions between the supercooled water-gas-hydrate metastable system and the self-preservation system were concluded as follows: One is that ice shell generation is essential for self-preservation; while in the supercooled water-gas-hydrate metastable system the hydrate persistence may be attributed to the kinetic difficulty of ice nucleation which could result in the decay of the hydrate metastability. Another is that the dissociation of metastable hydrates into supercooled water and gas is reversible; however, self-preserved hydrates would slowly and irreversibly dissociate into ice and gas [77]. In addition, the selfpreservation effect depends on the hydrate particle size, while the dependency in the supercooled water-gas-hydrate metastable system is not well consolidated. In the bulk hydrate dissociation at different back pressures, there might also be a metastable state of hydrate before water freezing is encountered. The existence of the metastable state will lower the gas production percentage and gas production rate. Not that system with additives or porous media would provide different equilibrium and boundary conditions, which should be separately discussed compared with pure system.

In the supersaturated liquid-gas-hydrate system, it was confirmed that hydrate can exist as metastable state when they were superheated based on the thermodynamics calculations and molecular dynamics simulations; the superheating limit for $T>273 \mathrm{~K}$ depends on the conditions of bubble nucleation from the liquid phase. This limit reflects the energy barrier to overcome to generate bubbles in the supersaturated liquid phase. Metastable hydrates can persist as long as the liquid surrounding the hydrate is supersaturated by the hydrate former (either dissolution in liquid at the supersaturation condition or in the form of

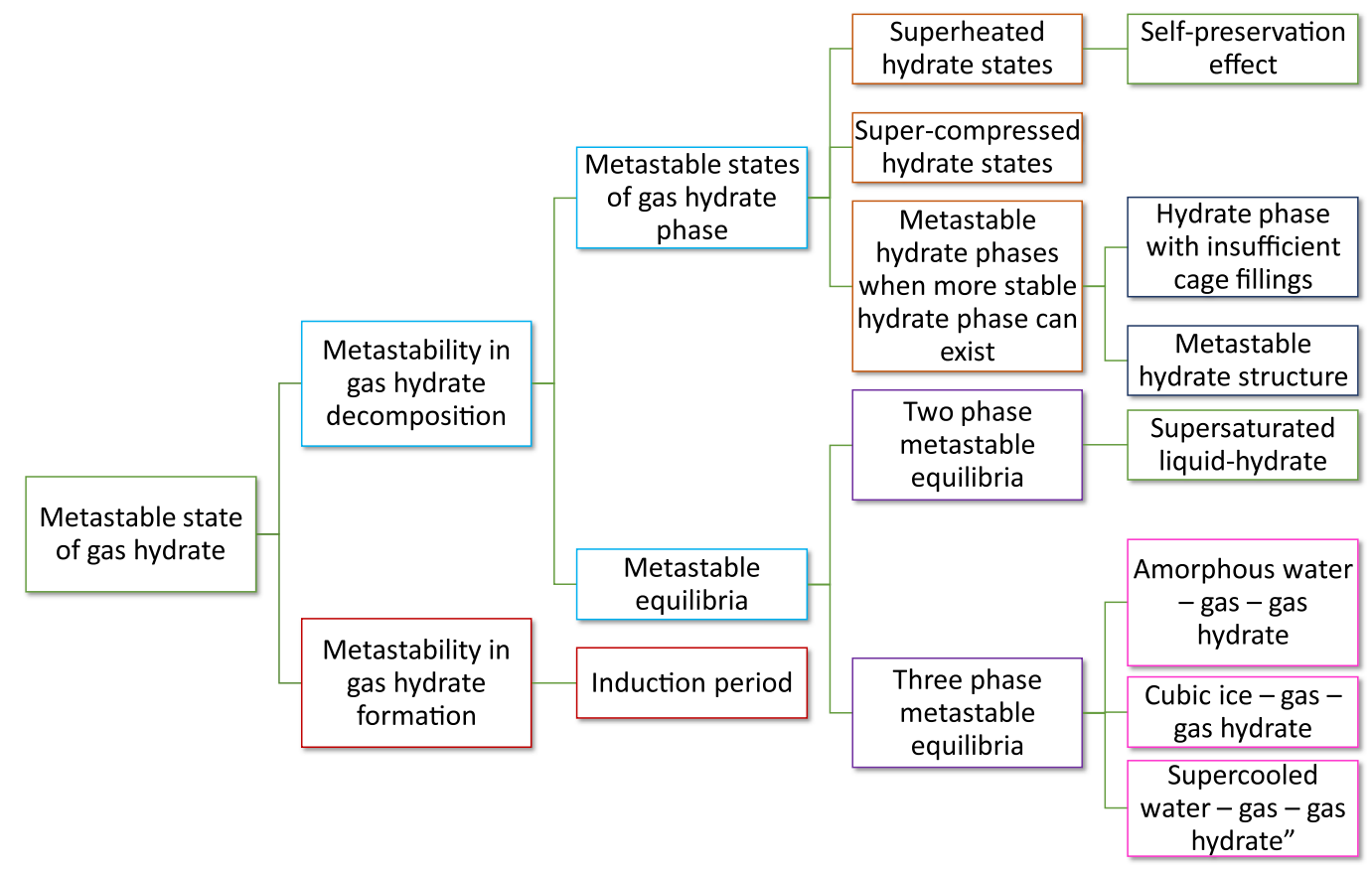

Fig. 3. Classifications of metastable states of gas hydrate. 
gas bubble); further gas dissolution in the liquid water and then into the gas phase would result in the deconstruction of hydrate cage $[34,54,55,78]$.

Hydrate of methane, ethane, propane, and carbon dioxide was generated in layers of gas-saturated amorphous ice using low-temperature molecular beams. Gas hydrate was observed to dissociate at an abnormally low rate; retention of hydrate during the dissociation process below $273 \mathrm{~K}$ was observed [79]. It was also predicted that the co-existence of $\mathrm{s}$ I and s II structure hydrate could occur by controlling the composition of methane-ethane mixture close to the s I/s II transition point; this is also considered as a metastable state of hydrate. The kinetic hydrate inhibitor could also play a role in hydrate metastability [80].

\section{Conclusions}

In this work, efforts on a novel phenomenon of metastable state of gas hydrate are introduced. The abnormally low rate of hydrate decomposition below $273 \mathrm{~K}$ could be of help in the gas storage and transportation. Yet, the metastable phenomena during the exploitation process of natural gas hydrate are rarely noted. Evidences of metastable gas hydrate in the reservoir are from the secondary hydrate formation during gas production and the outcrop hydrate in the cold seep system. Popular mechanisms of the metastable state of gas hydrate are described; it is indicated that those mechanisms could co-act. Further efforts are still required to better understand the stability of gas hydrate and its role in the fascinating kinetics of clathrates.

\section{Acknowledgements}

This study is supported by the National Key R\&D Program of China (Grant Nos. 2018YFC0310006 and 2017YFC0307300), the National Natural Science Foundation of China (Grant Nos. 51806027 and 51890911) and PetroChina Innovation Foundation.

\section{References}

[1] E.D. Sloan, C.A. Koh, Overview and historical perspective, Clathrate Hydrates of Natural Gases, Third editionCRC Press 2007, pp. 1-44

[2] L. Yang, Y. Liu, H. Zhang, B. Xiao, X. Guo, R. Wei, L. Xu, L. Sun, B. Yu, S. Leng, Y. Li, The status of exploitation techniques of natural gas hydrate, Chin. J. Chem. Eng. 27 (9) (2019) 2133-2147

[3] Z. Wu, Y. Li, X. Sun, P. Wu, J. Zheng, Experimental study on the effect of methane hydrate decomposition on gas phase permeability of clayey sediments, Appl Energ 230 (2018) 1304-1310

[4] A. Demirbas, Methane hydrates as potential energy resource: Part 1 - Importance resource and recovery facilities, Energy Convers. Manag 51 (2010) 1547-1561.

[5] Z. Wu, Y. Li, X. Sun, M. Li, R. Jia, Experimental study on the gas phase permeability of montmorillonite sediments in the presence of hydrates, Mar Petrol Geol 91 (2018) 373-380.

[6] L.G. Tang, X.S. Li, Z.P. Feng, G. Li, S.S. Fan, Control mechanisms for gas hydrate production by depressurization in different scale hydrate reservoirs, Energ Fuel 21 (2007) 227-233.

[7] T.A. Strobel, K.C. Hester, C.A. Koh, A.K. Sum, E.D. Sloan, Properties of the clathrates of hydrogen and developments in their applicability for hydrogen storage, Chem. Phys. Lett. 478 (2009) 97-109.

[8] H. Davy, The Bakerian lecture: on some of the combinations of oxymuriatic gas and oxygene, and on the chemical relations of these principles, To Inflammable Bodies, Philosophical Transactions of the Royal Society 101 (1800) 1-35.

[9] E.G. Hammerschmidt, Formation of gas hydrates in natural gas transmission lines, Industrial \& Engineering Chemistry 26 (1934) 851-855.

[10] Y.F. Makogon, S.A. Holditch, T.Y. Makogon, Natural gas-hydrates - A potential energy source for the 21st century, J. Pet. Sci. Eng. 56 (2007) 14-31.

[11] Y. Li, W. Liu, Y. Zhu, Y. Chen, Y. Song, Q. Li, Mechanical behaviors of permafrostassociated methane hydrate-bearing sediments under different mining methods, Appl Energ 162 (2016) 1627-1632.

[12] R. Boswell, Is gas hydrate energy within reach? Science (80- ) 325 (2009) 957-958

13] C.K. Paull, W.J. Buelow, W. Ussler, W.S. Borowski, Increased continental-margin slumping frequency during sea-level lowstands above gas hydrate-bearing sediments, Geology 24 (1996) 143-146.

[14] M. Hyodo, Y. Li, J. Yoneda, Y. Nakata, N. Yoshimoto, A. Nishimura, Effects of dissociation on the shear strength and deformation behavior of methane hydrate-bearing sediments, Mar Petrol Geol 51 (2014) 52-62.

[15] J. Yuan, Y. Hou, M. Xu, China's 2020 carbon intensity target: Consistency, implementations, and policy implications, Renew. Sust. Energ. Rev. 16 (2012) 4970-4981.
[16] J. Gudmundsson, Frozen hydrate for transport of natural gas, Proceedings of the 2nd International Conference of Natural Gas Hydrates, Toulouse, France, 1996 1996, pp. 415-422.

[17] J. Gudmundsson, F. Hveding, A. Børrehaug, Transport or Natural Gas as Frozen Hydrate, in: The Fifth International Offshore and Polar Engineering Conference, International Society of Offshore and Polar Engineers 1995.

[18] J. Gudmundsson, V. Andersson, O. Levik, M. Parlaktuna, Hydrate Concept for Capturing Associated Gas, in: European Petroleum Conference, Society of Petroleum Engineers 1998.

[19] A.D. Khawaji, I.K. Kutubkhanah, J.-M. Wie, Advances in seawater desalination technologies, Desalination 221 (2008) 47-69.

[20] J. Zhao, X. Guo, M. Sun, Y. Zhao, L. Yang, Y. Song, N2O hydrate formation in porous media: A potential method to mitigate N2O emissions, Chem. Eng. J. 361 (2019) 12-20.

[21] L. Yang, L. Ai, K. Xue, Z. Ling, Y. Li, Analyzing the effects of inhomogeneity on the permeability of porous media containing methane hydrates through pore network models combined with CT observation, Energy 163 (2018) 27-37.

[22] S.-Y. Lee, G.D. Holder, Methane hydrates potential as a future energy source, Fuel Process. Technol. 71 (2001) 181-186.

[23] N. Goel, M. Wiggins, S. Shah, Analytical modeling of gas recovery from in situ hydrates dissociation, J. Pet. Sci. Eng. 29 (2001) 115-127.

[24] G. Ahmadi, C. Ji, D.H. Smith, Production of natural gas from methane hydrate by a constant downhole pressure well, Energy Convers. Manag. 48 (2007) 2053-2068.

[25] A. Demirbas, Methane hydrates as potential energy resource: Part 2 - Methane production processes from gas hydrates, Energy Convers. Manag. 51 (2010) 1562-1571.

[26] Y. Wang, X. Li, G. Li, Y. Zhang, B. Li, J. Feng, A three-dimensional study on methane hydrate decomposition with different methods using five-spot well, Appl. Energy 112 (2013) 83-92.

[27] E. Sloan, C. Koh, Estimation techniques for phase Equilibria of natural gas hydrates, Clathrate Hydrates of Natural Gases (2008) 320-523.

[28] D. Kashchiev, A. Firoozabadi, Induction time in crystallization of gas hydrates, J. Cryst. Growth 250 (2003) 499-515.

[29] V. Yakushev, V. Istomin, Gas-hydrates self-preservation effect, Physics and Chemistry of Ice (1992) 136-139.

[30] P. Atkins, J. De Paula, Elements of Physical Chemistry, Oxford University Press, USA, 2013.

[31] J. Lubaś, B. Darłak, Metastability of natural gas hydrates in the presence of N2 and H2S, Journal of Energy Resources Technology 126 (2004) 125-132.

[32] V. Skripov, Metastable Liquids, Wiley, New York, 1974.

[33] G. Gu, G.R. Dickens, G. Bhatnagar, F.S. Colwell, G.J. Hirasaki, W.G.J.N.G. Chapman, Abundant Early Palaeogene marine gas hydrates despite warm deep-ocean temperatures, Nat. Geosci. 4 (2011) 848.

[34] B.A. Buffett, O.Y. Zatsepina, Metastability of gas hydrate, Geophys. Res. Lett. 26 (1999) 2981-2984.

[35] Y. Li, P. Wu, W. Liu, X. Sun, Z. Cui, Y. Song, A microfocus X-ray computed tomography based gas hydrate triaxial testing apparatus, Rev Sci Instrum 90 (2019), 055106.

[36] V.P. Melnikov, L.S. Podenko, A.O. Drachuk, N.S. Molokitin, A.M. Reshetnikov, Dissociation of gas hydrates produced from methane and "dry water" at temperatures below 273 K, Dokl. Phys. Chem. 461 (2015) 4945.

[37] Y. Nakajima, T. Takaoki, K. Ohgaki, S. Ota, Use of hydrate pellets for transportation of natural gas-II-proposition of natural gas transportation in form of hydrate pellets, Proc. 4th Int. Conf. Gas Hydrates 2002, pp. 987-990.

[38] M. Yang, Z. Fu, Y. Zhao, L. Jiang, J. Zhao, Y. Song, Effect of depressurization pressure on methane recovery from hydrate-gas-water bearing sediments, Fuel 166 (2016) 419-426.

[39] V. Yakushev, V. Istomin, The origin of gas blowouts from permafrost in Yamburg gas/condensate field, problems of gas fields development in permafrost conditions, The Digest/VNIIGAZ (1987) 119-127.

[40] Y.P. Handa, A calorimetric study of naturally occurring gas hydrates, Ind. Eng. Chem. Res. 27 (1988) 872-874.

[41] V. Yakushev, Gas-Hydrates Self-preservation Effect, Physics and Chemistry of Ice Hokkaido University Press, 1992.

[42] J. Gudmundsson, M. Parlaktuna, Gas-in-ice: Concept evaluation, Technical Report, University of Trondheim, The Norwegian Institute of Technology, Department of Petroleum Engineering and Applied Geophysics (1991).

[43] E. Ershov, V. Yakushev, Experimental research on gas hydrate decomposition in frozen rocks, Cold Reg. Sci. Technol. 20 (1992) 147-156.

[44] V. Melnikov, A. Nesterov, A. Reshetnikov, Gas hydrates dissociation at barometric pressure, Gazoviye Gidraty (Gas hydrates), 2005 55-61.

[45] V. Istomin, V. Kwon, V. Yakushev, Engineering Computations of Gas Hydrates Formation Conditions, The manual, Moscow, VNIIGAZ, 1989.

[46] L.A. Stern, S. Circone, S.H. Kirby, W.B. Durham, Anomalous preservation of pure methane hydrate at $1 \mathrm{~atm}, J$. Phys. Chem. B 105 (2001) 1756-1762.

[47] L.A. Stern, S.H. Kirby, W.B. Durham, S. Circone, W.F. Waite, Laboratory synthesis of pure methane hydrate suitable for measurement of physical properties and decomposition behavior, Natural Gas Hydrate, Springer 2000, pp. 323-348.

[48] W. Kuhs, G. Genov, D. Staykova, T. Hansen, Ice perfection and onset of anomalous preservation of gas hydrates, Phys. Chem. Chem. Phys. 6 (2004) 4917-4920.

[49] W. Kuhs, G. Genov, D. Staykova, T. Hansen, Ice Perfection and Anomalous Preservation of Gas Hydrates, in: Proceedings of the 5th International Conference on Gas Hydrates, Trondheim, Norway, 2005.

[50] V. Istomin, V. Kvon, S. Dolgaev, Metastability in Gas Hydrates Formation and Decomposition, in: Proceedings of the 7th International Conference on Gas Hydrates (ICGH 2011), Edinburgh, Scotland, United Kingdom, 2011.

[51] V.P. Melnikov, A.N. Nesterov, L.S. Podenko, A.M. Reshetnikov, V.V. Shalamov, NMR evidence of supercooled water formation during gas hydrate dissociation below the melting point of ice, Chem. Eng. Sci. 71 (2012) 573-577. 
[52] V.P. Melnikov, A.N. Nesterov, A.M. Reshetnikov, Formation of supercooled water upon dissociation of propane hydrates at $T<270$ K, Dokl. Phys. Chem. 417 (2007) 304-307.

[53] V.P. Melnikov, A.N. Nesterov, A.M. Reshetnikov, A.G. Zavodovsky, Evidence of liquid water formation during methane hydrates dissociation below the ice point, Chem. Eng. Sci. 64 (2009) 1160-1166.

[54] T. Yagasaki, M. Matsumoto, Y. Andoh, S. Okazaki, H. Tanaka, Effect of bubble formation on the dissociation of methane hydrate in water: A molecular dynamics study, $J$. Phys. Chem. B 118 (2014) 1900-1906.

[55] L. Yang, A. Falenty, M. Chaouachi, D. Haberthür, W.F. Kuhs, Synchrotron X-ray computed microtomography study on gas hydrate decomposition in a sedimentary matrix, Geochem. Geophys. Geosyst. 17 (2016) 3717-3732.

[56] Y. Handa, Calorimetric determinations of the compositions, enthalpies of dissociation, and heat capacities in the range 85 to $270 \mathrm{~K}$ for clathrate hydrates of xenon and krypton, J. Chem. Thermodyn. 18 (1986) 891-902.

[57] C.G. Pruteanu, G.J. Ackland, W.C. Poon, J.S. Loveday, When immiscible becomes miscible-methane in water at high pressures, Sci. Adv. 3 (2017), e1700240.

[58] Y.V.S. Istomin, A. V, N.A. Makhonina, et al., Self-preservation Phenomenon of Gas Hydrate, Gas Industry of Russia, 2006 16-27.

[59] J.S. Gudmundsson, M. Parlaktuna, A. Khokhar, Storage of natural gas as frozen hydrate, SPE Production \& Facilities 9 (1994) 69-73.

[60] T. Ebinuma, S. Takeya, E.M. Chuvilin, Y. Kamata, T. Uchida, J. Nagao, H. Narita, Dissociation behaviors of gas hydrates at low temperature, Proc. 4th International Hydrate Conference 2002, pp. 19-23.

[61] A. Falenty, W.F. Kuhs, M. Glockzin, G. Rehder, "Self-preservation" of $\mathrm{CH}_{4}$ hydrates for gas transport technology: pressure-temperature dependence and ice microstructures, Energ Fuel 28 (2014) 6275-6283.

[62] A. Falenty, W.F. Kuhs, "Self-preservation" of $\mathrm{CO}_{2}$ gas hydrates-surface microstructure and ice perfection, J. Phys. Chem. B 113 (2009) 15975-15988.

[63] V. Istomin, On the possibilities of natural gas hydrates and other water crystalline structures superheating, Zhurnal Fizicheskoi Khimii (Journal of Physical Chemistry) 73 (1999) 2091-2095.

[64] O.I. Levik, Thermophysical and compositional properties of natural gas hydrate, Ph. D Thesis, Norwegian University of Science and Techhnology, Norway, 2000.

[65] V. Istomin, On possibility of superheating of natural gas hydrates and other hydrogencontaining crystalline structures, Russ. J. Phys. Chem. 73 (1999) 1887-1890.

[66] S. Takeya, T. Ebinuma, T. Uchida, J. Nagao, H. Narita, Self-preservation effect and dissociation rates of CH4 hydrate, J. Cryst. Growth 237 (2002) 379-382.
[67] S. Takeya, W. Shimada, Y. Kamata, T. Ebinuma, T. Uchida, J. Nagao, H. Narita, In situ $\mathrm{X}$-ray diffraction measurements of the self-preservation effect of $\mathrm{CH}_{4}$ hydrate, $J$. Phys. Chem. A 105 (2001) 9756-9759.

[68] W. Lin, G.J. Chen, C.Y. Sun, X.Q. Guo, Z.K. Wu, M.Y. Liang, L.T. Chen, L.Y. Yang, Effect of surfactant on the formation and dissociation kinetic behavior of methane hydrate, Chem. Eng. Sci. 59 (2004) 4449-4455.

[69] X. Wang, G. Chen, C. Sun, L. Yang, Q. Ma, J. Chen, P. Liu, X.l. Tang, H. Zhao, W. Chen, The dependence of the dissociation rate of methane-SDS hydrate below ice point on its manners of forming and processing, Chin. J. Chem. Eng. 17 (2009) 128-135.

[70] M. Liang, G. Chen, C. Sun, L. Yan, J. Liu, Q. Ma, Experimental and modeling study on decomposition kinetics of methane hydrates in different media, J. Phys. Chem. B 109 (2005) 19034-19041.

[71] S. Takeya, T. Uchida, J. Nagao, R. Ohmura, W. Shimada, Y. Kamata, T. Ebinuma, H. Narita, Particle size effect of $\mathrm{CH}_{4}$ hydrate for self-preservation, Chem. Eng. Sci. 60 (2005) 1383-1387.

[72] S. Circone, L.A. Stern, S.H. Kirby, The effect of elevated methane pressure on methane hydrate dissociation, Am. Mineral. 89 (2004) 1192-1201.

[73] B. Mason, G. Bryant, A. Van den Heuvel, The growth habits and surface structure of ice crystals, Philos. Mag. 8 (1963) 505-526.

[74] A. Falenty, T.C. Hansen, W.F. Kuhs, Formation and properties of ice XVI obtained by emptying a type sII clathrate hydrate, Nature 516 (2014) 231-233.

[75] V.P. Melnikov, A.N. Nesterov, A.M. Reshetnikov, V.A. Istomin, V.G. Kwon, Stability and growth of gas hydrates below the ice-hydrate-gas equilibrium line on the PT phase diagram, Chem. Eng. Sci. 65 (2010) 906-914.

[76] V.P. Melnikov, A.N. Nesterov, A.M. Reshetnikov, V.A. Istomin, Metastable states during dissociation of carbon dioxide hydrates below 273K, Chem. Eng. Sci. 66 (2011) 73-77.

[77] M.S. Madygulov, A.N. Nesterov, A.M. Reshetnikov, V.A. Vlasov, A.G. Zavodovsky, Study of gas hydrate metastability and its decay for hydrate samples containing unreacted supercooled liquid water below the ice melting point using pulse NMR, Chem. Eng. Sci. 137 (2015) 287-292.

[78] Y. Kuang, X. Lei, L. Yang, Y. Zhao, J. Zhao, Observation of in situ growth and decomposition of carbon dioxide hydrate at gas-water interfaces using magnetic resonance imaging, Energ Fuel 32 (2018) 6964-6969.

[79] M.Z. Faizullin, A.V. Vinogradov, V.P. Koverda, Hydrate formation in layers of gas-saturated amorphous ice, Chem. Eng. Sci. 130 (2015) 135-143.

[80] H. Ohno, T.A. Strobel, S.F. Dec, J.E.D. Sloan, C.A. Koh, Raman studies of methane ethane hydrate metastability, J. Phys. Chem. A 113 (2009) 1711-1716. 